\title{
Correction to: Tooth-coloured materials for class II restorations in primary molars: systematic review and meta-analysis
}

\author{
V. Siokis ${ }^{1} \cdot$ T. Michailidis $^{2} \cdot$ N. Kotsanos ${ }^{1}$
}

Published online: 2 November 2021

(c) European Academy of Paediatric Dentistry 2021

Correction to: European Archives of Paediatric Dentistry
https://doi.org/10.1007/s40368-021-00632-3

After publication, it was noticed that the author names were abbreviated incorrectly in the original article. The correct author names are given as:

V. Siokis, T. Michailidis, N. Kotsanos.

Publisher's Note Springer Nature remains neutral with regard to jurisdictional claims in published maps and institutional affiliations.

The original article can be found online at https://doi.org/10.1007/ s40368-021-00632-3.

V. Siokis

vasileios.siokis@yahoo.com

1 Department of Paediatric Dentistry, Aristotle University of Thessaloniki, Thessaloniki, Greece

2 Medical School, Aristotle University of Thessaloniki, Thessaloniki, Greece 